\title{
Historical Perspective of Periodontal Progenitor Cells: Early Studies That Clarified Identity and Function
}

\author{
Christopher A. McCulloch ${ }^{1,2}$
}

Published online: 9 September 2015

(C) Springer International Publishing AG 2015

\begin{abstract}
Pioneering studies using cell kinetics, transplantation and wound healing models that were conducted in the 1960s-1980s provided critical insights into the proliferative and differentiation capacity of cell populations in the periodontium. These experiments showed that the periodontium, in general, and the periodontal ligament, in particular, comprise progenitor cell populations that can give rise to cells that synthesize bone, cementum and fibrous connective tissue. These insights ultimately led to the discovery of multipotent progenitors that are just now being studied to define their contributions to periodontal regeneration. Despite the limitations that were inherent in these earlier approaches, data from these experiments enabled major strides in exploiting the transformative potential of stem cell biology to provide improved outcomes in periodontal therapy.
\end{abstract}

Keywords Cell kinetics $\cdot$ Stem cells $\cdot$ Periodontal ligament . Cell proliferation $\cdot{ }^{3} \mathrm{H}-\mathrm{Tdr}$

This article is part of the Topical Collection on Stem-Cell Biology for Tooth and Periodontal Regeneration

Christopher A. McCulloch

christopher.mcculloch@utoronto.ca

1 Matrix Dynamics Group, Faculty of Dentistry, University of Toronto, Toronto, ON, Canada

2 University of Toronto, Room 244, Fitzgerald Building, 150 College Street, Toronto, ON M5G 1G6, Canada

\section{Introduction: Why Are We Interested in Progenitor Cells of the Periodontium?}

In periodontology, clinicians have made major efforts to develop a better fundamental understanding of tissue structure and function and apply this knowledge for improved patient care. Treatments for periodontitis, a historically high prevalence disease of mankind [1], are a good example of this search process, which has played out over the last three centuries. The eighteenth century, British surgeon-scientist, John Hunter, focused some of his considerable scientific energies on devising new treatments for periodontitis. Hunter recognized that, in particular, new and effective treatments would need to be linked to a better understanding of the development of periodontal tissues. Based on ingenious xenografting experiments (Fig. 1), he reasoned that the limited healing after then current treatment approaches was because periodontal wound healing did not recapitulate the processes that occur in periodontal development. Much more recent research has uncovered some of the challenges associated with regenerative healing in periodontal tissues [2], which arise in part from the complexity of the cell populations that are found in these tissues. In this context, the periodontium, which attaches the roots of the teeth to the alveolar bone, comprises two somewhat similar mineralized connective tissues, cementum and alveolar bone, and two fibrous and remarkably cellular soft connective tissues, the lamina propria of the gingiva and the periodontal ligament $(\mathrm{PL})$. Our detailed understanding of the structural and functional roles played by cementum, PL, alveolar bone and gingival lamina propria in periodontal function [3] may have diverted researchers from delving into the underlying complexities of the composition and regulation of the cell populations that make up periodontal tissues. Here, we consider earlier research on cell proliferation and differentiation in periodontal tissues, which have led to our current 


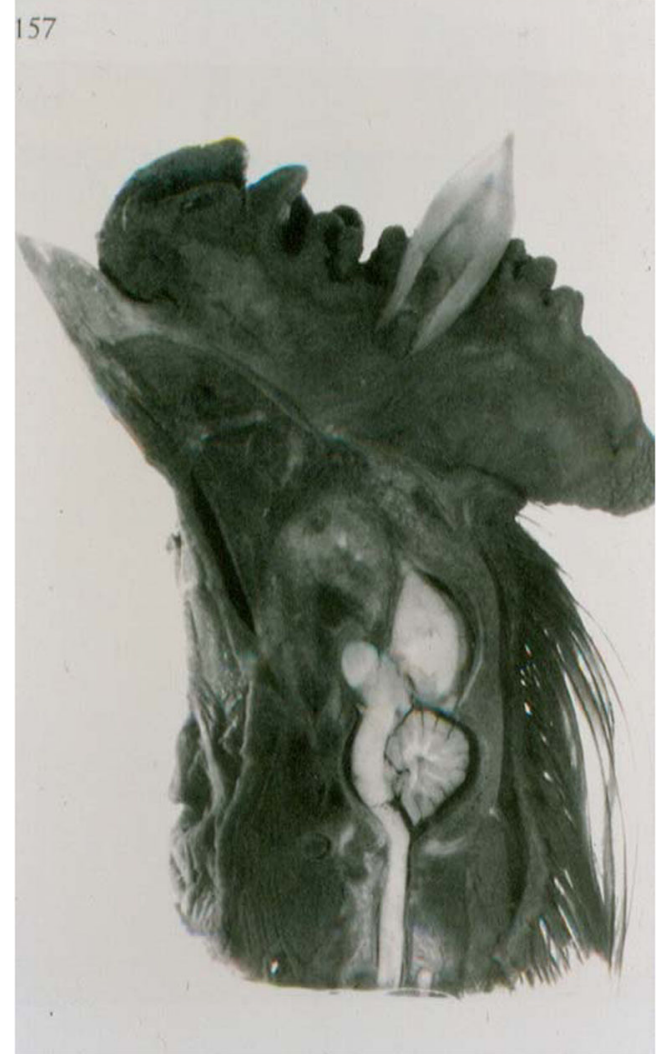

Fig. 1 A photograph of a specimen from the Hunterian Museum in London, England, showing the results of an experiment conducted by John Hunter in the 1700s. A human tooth germ has been apparently transplanted into the comb of a rooster, which may have provided an immunologically privileged site for a certain amount of tooth development and possible development of the periodontium

understanding of periodontal progenitor cells and how the regulation of these cells may provide essential clues for improving outcomes after periodontal regenerative therapies.

\section{The PL and Its Central Role in Homeostasis and Wound Healing}

It has been known for many years that the functions of the PL include proprioception, tooth support and attachment [4]; these latter functions are evidently provided by the principal collagen fibres of the PL, which undergo rapid turnover in health [5]. Homeostasis of the PL and contiguous periodontal tissues is maintained by cells that include formative and resorptive cells for cementum, PL and bone. In contrast to the rapid collagen turnover in the PL [5], the turnover of cells is very slow [6]. Under normal conditions of function, these cells are actively engaged in protein metabolism for PL homeostasis rather than in proliferation, but their exact role in regeneration was not known. Expert clinicians have provided evidence to show that under favourable circumstances, periodontal regeneration was possible [7], but the determinants of successful treatment at the cellular level were not defined. The recognition that cells of the PL play critical roles in periodontal regeneration [8] and may contribute to the formation of new cementum, bone and PL generated considerable interest in the proliferative and differentiation capacity of these cell populations.

In the 1960s, 1970s and 1980s, most of our understanding of the contribution of periodontal cell populations to regeneration came from morphological, wound healing and transplantation studies, as well as the clever use of cell kinetic methods to examine cell origins and fate. Insights from these experiments were instrumental in advancing our current understanding of progenitor cells in the periodontium and their contributions to periodontal regeneration. In the next section, research approaches used in the 1960s-1980s will be discussed in order to place the notion of progenitor and stem cells in a larger perspective.

\section{Experimental Approaches for Investigating Progenitor Cells and Cell Turnover}

The rate of turnover of cells varies considerably between different tissues: while no new cell production occurs in the neurons of the central nervous system, turnover of the epithelial cells in the small intestine can be as fast as 3 days [9]. Cell population kinetic studies involve the clarification and quantification of proliferation, differentiation, migration and death of cells within a definable cell population [10]. An essential requirement of cell proliferation is that each daughter cell should have exactly the same genome as the parent cell. For this reason, the mother cell's DNA must be replicated prior to cell division. Howard and Pelc [11] discovered, by monitoring the uptake of radioactively labelled nucleotide precursors, that DNA is synthesized during a limited part of interphase and not during cell division. They proposed the concept of a cell cycle, during which the cell goes through recognizable phases between one mitosis and the next. The period of DNA synthesis was designated the $\mathrm{S}$ phase; the periods preceding and following DNA synthesis were denoted $\mathrm{G}_{1}$ and $\mathrm{G}_{2}$, respectively, and represent gaps in the proliferative cycle. $G_{2}$ was followed by mitosis and, it in its turn, by $\mathrm{G}_{1}\left(\right.$ or $\left.\mathrm{G}_{0}\right)$.

Charles LeBlond of McGill University in Montreal [9] described cell populations as "being groups of cells with a common origin and the same morphological and functional potential," and he and his colleagues used the techniques of cell kinetics to group different mammalian tissues on the basis of their proliferative behaviour. Leblond and his colleagues [12] used two parameters to characterize cell populations: the rate at which cells incorporate ${ }^{3} \mathrm{H}-$ Tdr into DNA and the rate at which labelled cells are lost from the tissue. Two tests were used to measure these parameters, a cell formation test and a cell retention test. 
In the cell formation test, rats and mice were injected with $3 \mathrm{H}-\mathrm{Tdr}$ (ages of either 3 days or 6 months old) and killed within a few hours after injection. The fraction of labelled cells in a number of different tissues was determined by radioautography. In the cell retention test, animals were injected with ${ }^{3} \mathrm{H}-\mathrm{Tdr}$ when they were 3 days old and killed when they were 6 months old, and the fraction of labelled cells was determined as stated above. Tissues such as smooth muscle, cardiac muscle and neurons of the cerebrum exhibited no labelling in the cell formation test and minimal labelling in the cell retention test: these were termed static cell populations. They could not divide, but their precursors could divide and differentiate into end cells which were incapable of further mitoses. In the proximal convoluted tubules of the kidney, parenchymal cells of the liver and the epithelial cells of the thyroid gland, a small percentage of cells, were labelled in both the cell formation and cell retention tests so that there was both limited cell division and cell retention throughout the adult life of the animal. In addition, the daily increase in cell number was about equal to the daily mitotic rate [13], and therefore, new cells were retained in situ, thereby expanding the size of the cell population with age. These were expanding cell populations.

In the epithelial cells of the small intestine, the cortical cells of the thymus, bone marrow cells and the epithelial cells of the tongue, many cells were labelled in the cell formation test at 3 days and 6 months, but none was labelled in the cell retention test. These tissues contain cells that divide frequently and thereby dilute their label through successive cell divisions until it is not detectable. The high mitotic activity is balanced by cell loss as a result of migration or death, and the size of the cell population is maintained in a steady state. These cells comprise renewal populations.

However, there were three tissues that did not fit into these classifications. Dermal connective tissue, lung alveolar tissue and cells of the PL of continuously erupting incisors exhibited high labelling indices in the cell formation test and low labelling indices in the cell retention test. It was not expected that labelled cells would be renewed or lost from these tissues. Leblond [12] therefore concluded that "connective tissue cells may constitute a mixed cell population with very different proliferative potencies, or else local conditions determine whether or not connective tissue cells are to divide." Cameron [14] subdivided renewal cell populations into rapidly and slowly renewing. On the basis of data from a continuous labelling experiment, he classified the PL as a slowly renewing tissue. Later data obtained from continuous ${ }^{3} \mathrm{H}-\mathrm{Tdr}$ labelling experiments showed that there is indeed a renewal cell population in PL, but there is also a static, non-dividing cell population that may be formed during PL development and that does not undergo renewal or turnover thereafter [15].

\section{Concepts of Stem Cell, Transit Cell and Static Cell Populations}

In certain renewal tissues such as the epithelium of the seminal vesicles, cells throughout the tissue have the capacity to divide [16]. However, in most tissues with renewing cell populations, such as the stratified squamous epithelium of the oesophagus, cell division is restricted to the relatively undifferentiated cells of the basal cell layers [13]. In the oesophagus, the migration of cells into the spinous and granular layers is accompanied by increasing differentiation and loss of proliferative potential. On the basis of these and other data, Leblond proposed that proliferation is restricted to relatively undifferentiated cells, which he denoted as stem cells while differentiation occurred in post-mitotic cells. By contrast, in haematopoiesis and spermatogenesis, cell replacement by mitosis was observed in differentiating cell compartments in which further differentiation and maturation may occur [17]. In this model, the proliferative compartment is double (or multitiered) because it contains self-renewing cells and cells committed to terminal maturation that can undergo further rounds of cell division. These latter cells were denoted as transit cells. It was thought that if the burden of proliferation rests solely on self-renewing (stem) cells, large genetic pressures would compromise the integrity of the stem cell DNA because of the large number of replications that occur during the life of the organism.

In a multitier proliferative model, stem cells cycle slowly, but their transit cell progenies are responsible for the bulk of proliferation and do so by repeated cell divisions [17]. Transit cells were thought to be derived from stem cells and would have a finite life span governed by loss of proliferative capacity and expulsion from the tissue [18]. Using the criteria of proliferation alone, transit cells cannot be distinguished from stem cells, although it had been suggested that the proliferative rate of stem cells is low in blood-forming tissues [19] and epidermis [20]. It was known that the turnover rates of these tissues cannot be accounted for solely on the basis of stem cell proliferation [17]. Repeated division in the transit cell populations would account for the bulk of cell division in a multitier model of proliferation [18]. The essential functional difference between stem cell and transit cell populations is the proliferative lifetime of the population [17]. Stem cell function relies on self-renewal during the entire lifetime of the animal; otherwise, the tissue would die. Transit cell populations have a limited lifetime although, while proliferating, they have a tremendous amplification potential. Ten cell divisions in a population of transit cells could result in a 1000-fold increase in cell number [18].

Static cell populations are built up during an early stage of development of the organism, lose the ability to divide [13] and are usually present in slowly decaying numbers [18]. The neurons of the central nervous system, muscle cells and oocytes are examples of such cells. They will not take up ${ }^{3} \mathrm{H}-\mathrm{Tdr}$ 
after a pulse injection because they do not proliferate. The important difference between static cells and cells of expanding cell populations is the ability to divide. Liver cells (which belong to expanding cell populations) do not divide rapidly under normal conditions but can be stimulated to divide after partial liver resection [21]. Static cell populations are not capable of such a response to wounding, and this explains the irreversible damage to cells of the central nervous system after injury.

\section{What Are Stem Cells?}

The stem cell has been functionally defined as a "cell having the capacity for extensive proliferation resulting in renewal of its own kind as well as giving rise to a differentiated cell" [22]. During embryogenesis, stem cell populations expand from the initial stem cell, the zygote. As differentiated cell lines appear, the ratio of functional cells to stem cells increases, and with maturity and the achievement of steady-state conditions, the number of stem cells remains constant in the adult [23]. The degree of differentiation of the stem cell is relative to the tissue and the age of organism, and stem cells for a particular cell lineage are rarely undifferentiated [18]. Up until recently, it has been difficult to isolate stem cells with stem cell-specific markers. Early work [24] used morphological criteria to tentatively identify epidermal stem cells or the use of antibodies [25] against putative hematopoietic stem cells. A cell capable of self-renewal and demonstrating the ability to produce large numbers of progeny with more than one phenotype is considered to be a pluripotent stem cell [26]. Potten [17] enumerated the expected properties of stem cells (Table 1).

Table 1 Criteria for stem cells from the early 1980s

\begin{tabular}{|c|c|}
\hline $\begin{array}{l}\text { Criterion } \\
\text { number }\end{array}$ & Criterion \\
\hline 1 & Be precursors for specialized cells \\
\hline 2 & Be capable of self-renewal \\
\hline 3 & Demonstrate regenerative or clonogenic capacity \\
\hline 4 & $\begin{array}{l}\text { Exhibit sparse distribution within the proliferative } \\
\text { compartment }\end{array}$ \\
\hline 5 & Respond to control mechanisms, \\
\hline 6 & Have a long cell cycle time and hence a long $\mathrm{G}_{0}$ period, \\
\hline 7 & $\begin{array}{l}\text { Possess a mechanism for conservation of the } \\
\text { integrity of DNA }\end{array}$ \\
\hline 8 & Demonstrate a characteristic thymidine metabolism \\
\hline
\end{tabular}

\section{Searching for Stem Cells}

One of the early studies to examine the stem cell concept was the work of James Till and Ernest McCulloch at the Ontario Cancer Institute [27]. They injected bone marrow suspensions into lethally irradiated mice and found that the mice could survive because of the following: (1) the repopulation of the haematopoietic system, (2) the clonogenic capacity of the hematopoietic stem cells in the suspension and (3) their extensive capacity for self-renewal. They extended this experimental approach with ${ }^{3} \mathrm{H}-\mathrm{Tdr}$ suicide experiments combined with a spleen colony assay system to show that the proliferative rates of colony-forming unit-stem cells (CFU-S) were considerably higher in foetal liver and spleen than adult marrow or spleen [19]. These data suggested that the CFU-S were regulated by the rate of production of blood cells and that in the adult, when the steady state is obtained, few CFU-S are traversing the cell cycle. They remain in a resting or $\mathrm{G}_{0}$ part of the cell cycle. The same group [28] showed that a single, cytogenetically marked hematopoietic pluripotent stem cell can produce colonies of heterogeneous differentiated cells. These observations taken together suggest that the CFU-S fulfils most of the criteria for a putative stem cell as outlined earlier [17].

In epidermis, transplanted epidermal stem cells exhibit considerable capacity for regeneration and self-renewal and they can generate differentiated cells in irradiated sites deprived of epidermal stem cells [6]. Epidermal stem cells have a slow turnover rate, a prolonged $\mathrm{G}_{0}$ and a rate of proliferation that is sensitive to external factors such as irradiation [29]. It has been suggested that the nascent DNA of epithelial stem cells is not semi-conserved upon cell division. Instead, the newly synthesized DNA, which is more subject to errors of replication, is sequestered in one of the daughter cells [30]. Indirect experimental evidence to substantiate the selective segregation of DNA in epithelial stem cells came from examination of radioautographs of ${ }^{3} \mathrm{H}-\mathrm{Tdr}$-labelled mouse skin [31]. Cells which occupied the position of stem cells were initially labelled and then passed their nascent labelled DNA to one of the daughter, migratory cells. The stem cells thereafter were unlabelled. These data are not consistent with other work showing that putative stem cells in the skin are labelled and cycle very slowly [32].

\section{Cell Populations in the PL}

Despite the many characteristics attributed to stem cells described above, these cells remain difficult to identify and separate in most mammalian tissues; the PL is no exception. Work conducted by Melcher and colleagues at the University of Toronto showed that (1) in both steady-state and wounding conditions, the regions around blood vessels in the PL 
(paravascular sites) were enriched with progenitor cells [33, 34]; (2) these progenitors could give rise to fibroblasts, cementoblasts and osteoblasts; (3) the PL was not a closed cell system, but instead, cells from adjacent endosteal spaces migrated into the PL and there contribute to the progenitor cell populations that could synthesize bone, cementum and PL [35].

\section{Experimental Challenges of Identifying Progenitor Cells}

It is difficult to discriminate fibroblasts from macrophages in the light microscope [36]. Thin plastic sections have been used to improve the accuracy of cell identification and so partially overcome this difficulty [37]. In another approach to improve cell identification [34], animals were irradiated to lower the number of circulating monocytes and, correspondingly, the number of labelled macrophages that could be identified as fibroblasts and, second, identified labelled cells by their ultrastructure. Further, when animal models employing sacrifice times greater than 1 day are used, it is uncertain whether all ${ }^{3} \mathrm{H}$-Tdr-labelled cells are derived from cells initially resident in the PL.

Another general problem with application of cell kinetic methods in the PL is the low level of cell proliferation under physiological conditions [38]. To derive data of ${ }^{3} \mathrm{H}-\mathrm{Tdr}$ labelling index that can be analyzed statistically, large numbers of cells must be counted. This can be accomplished by either using many sections from a small number of animals or vice versa. In this context, analysis of variance [39] of osteoclast histogenesis in the PL indicated that designs in which the numbers of animals are increased are preferable to designs with more sections per animal. Stimulations of the PL by wounding [40], orthodontic tooth movement [41] or heat [42] have also been used to increase the rate of cell proliferation and so address in part these statistical problems. However, because there is massive cell death in these experimental systems, steady-state conditions do not exist and those factors that regulate proliferation under normal function can only be surmised.

\section{Origin and Kinetics of Cells Resident in the PL: Fibroblasts}

Debate over the origins of fibroblasts began with Virchow (1871) [43] who favoured local division of undifferentiated mesenchymal cells while Maximow (1926) [44] suggested a hematogenous origin after observing a rapid accumulation of cells in tissue culture without obvious increase of local mitotic activity. Experiments by Russell Ross and colleagues [36] clarified this issue with a parabiotic model in which the identity of labelled cells was established using electron microscopy. These data demonstrated that fibroblasts taking up ${ }^{3} \mathrm{H}-\mathrm{Tdr}$ after wounding are not blood-borne and that proliferation is associated with local division of cells closely associated with blood vessels. A follow-up in vitro study of human bone marrow fibroblasts [45] added further support to the belief in separate origins for fibroblasts and macrophages.

PL fibroblasts may originate embryologically from the dental follicle [46], and an electron microscope examination of developing mouse tooth germs [47] demonstrated that cell division was confined to paravascular cells. The cells of the investing layer around the developing PL exhibited the ultrastructural characteristics of "undifferentiated fibroblasts" [48]. Gould et al. [34, 40] used stathmokinetic agents and ${ }^{3} \mathrm{H}-\mathrm{Tdr}$ labelling with radioautography to identify proliferating cells in wounded PL of adult mouse molars. At $30 \mathrm{~h}$ after wounding, uptake of ${ }^{3} \mathrm{H}-\mathrm{Tdr}$ by cells was maximal and the labelling index curve closely resembled that of liver after partial hepatectomy [21], indicating that PL cells could be stimulated to entry into the cell cycle by wounding. Labelled cells were initially located paravascularly, but after 3 days of healing, labelled cells were seen at a distance of up to $100 \mu \mathrm{m}$ from blood vessels. This indicated a migration of proliferating cells away from the paravascular zone. Both undifferentiated and cytodifferentiated paravascular cells took up the ${ }^{3} \mathrm{H}-\mathrm{Tdr}$ label as demonstrated by the electron microscope radioautographs. Some of the labelled cells contained collagen in phagosomes, which suggested a more differentiated state. This last observation has received further substantiation from data [49] showing that in the PL of the rat molar stimulated by orthodontic tooth movement, dividing fibroblasts exhibited collagen-containing phagosomes.

A functional analysis of stem cells as demonstrated in the blood-forming system [27] has not yet been conducted for PL fibroblasts. However, phenotypic and functional differences of PL cells compared with those of other connective tissues have been examined in combined cell culture/transplantation experiments. In one report, the roots of dog teeth were incubated with connective tissue cells from either PL, skin or gingiva; the roots were then implanted in bone [50]. Only fibroblasts from PL formed structures that resembled the PL. A phenotypic difference between PL and skin fibroblasts derived from Macaca irus has also been demonstrated in culture [51].

The kinetics of PL fibroblasts have been investigated in detail using mitotic counts and labelling with injected ${ }^{3} \mathrm{H}-$ Tdr. The large inter-animal variation, diurnal periodicity and difficulty in localizing mitotic cells accurately in thick paraffin sections caused early investigators [52] to report mitotic indices with large variations in normally functioning rat molar PL. Later workers [53] examined rat molar PL and found that ${ }^{3} \mathrm{H}-$ Tdr-labelled cells were located preferentially in the bone half of the PL. Further, labelled cells were most abundant in the 
bifurcation zones of the PL and higher at the apical and coronal levels of the root compared to the middle of the root. The authors suggested that the tooth rotates very slightly about an axis located at the level of the middle of the root and that the increased function at the coronal and apical portions of the root accounts for the higher labelling indices. No evidence was presented which detected or measured "function," and indeed, later studies [54] found no gradient of ${ }^{3} \mathrm{H}$-proline uptake in the PL of rat molars at different levels of the root. Because most of the protein metabolism in the PL involves collagen [55], it is reasonable to assume that ${ }^{3} \mathrm{H}$-proline uptake in PL measures collagen synthesis.

When PL cell proliferation was examined in rats, the labelling indices were $~ 9$-fold higher in 30-day rats than 400-day rats [56], data that are consistent with observations of aging fibroblasts in culture [57, 58]. Shorter life spans and progressively fewer cell population doublings were observed in cultures originating from adult human tissues compared with cultures prepared from foetal tissue. Studies of PL cell proliferation were also conducted in aging mice [59], and these data were interpreted as providing evidence for a pluripotent cell labelled with ${ }^{3} \mathrm{H}-\mathrm{Tdr}$ that could produce differentiated progeny for the synthesis of cementum, PL and bone.

The turnover time of PL cells was studied with the use of continuous labelling of ${ }^{3} \mathrm{H}-\mathrm{Tdr}$ in the drinking water of mice to label all proliferating cells [14]. After 30 days of labelling, $50 \%$ of the PL cells were labelled, suggesting that the PL is a renewal tissue and that its turnover time is $\sim 60$ days. In contrast, if the turnover time is calculated from the birth rate and the mean labelling index derived from a ${ }^{3} \mathrm{H}-\mathrm{Tdr}$ pulse label experiment, then the turnover time is about 20 days [60]. The reason for this difference is the assumption in the calculated turnover time that all cells in the PL are cycling, which may not be correct based on later data showing that after prolonged labelling with ${ }^{3} \mathrm{H}-\mathrm{Tdr}$ in the drinking water of mice, many of the PL cells were not labelled [15]. The identity and function of these non-proliferating cells in the PL have not been resolved.

When rat molar teeth are subjected to orthodontic forces, there are very large increases of the PL labelling index $[61,62]$, which may be attributable to entry of cells into the cell cycle and expansion of the proliferating fraction of cells. Another report suggested that cells in the normally functioning PL are released from $\mathrm{G}_{2}$ block by orthodontic force [63, 64]. Collectively, these data indicate the recruitment of non-proliferating cells into the cell cycle for generating repopulation responses in the PL. Further, measurements of nuclear volume density of proliferating PL cells indicate that there are separate progenitor populations for osteoblasts and fibroblasts in the PL [65].

\section{Osteoblasts}

Three experimental systems were used extensively in the 1960s-1970s to evaluate osteoblast histogenesis: (1) regeneration of marrow after depletion of the marrow cavity, (2) transplantation of marrow to an ectopic site and (3) culture of marrow stromal cells. The common finding from the first two methods is that marrow stroma and osteogenic soft connective tissue are both capable of producing bone tissue and marrow stroma $[66,67]$. The production of marrow stroma relies upon the prior formation of bone tissue and that haematopoiesis is initiated at sites of bone resorption [68]. The third method utilized an in vivo/in vitro system pioneered by Friedenstein [69]. Fibroblast colonies were formed from a single-cell suspension derived from marrow tissue and grown in vitro. When these cells were placed in a diffusion chamber with thymus cells and implanted subcutaneously, viable mineralized tissue was formed which, upon light and electron microscopic examination, closely resembled bone.

Friedenstein [69] described two classes of bone progenitors, the determined osteogenic precursor cell (DOPC), which generates colony-forming units in culture and which exhibits extensive self-renewal without heterogenic inductive stimuli, and the inducible osteogenic precursor cell (IOPC) which requires stimulation for bone formation. Pre-osteoblasts in vivo are likely to be the DOPCs because they are capable of selfrenewal throughout the life of the organism. The existence and the location of the stem cell for osteoblasts were not definitively demonstrated although they were more abundant near bone surfaces [70].

Little work has been done on the local origin of osteoblasts in the PL. In one experiment, ${ }^{3} \mathrm{H}$-Tdr-labelled ectomesenchymal cells of dental follicle were transplanted into adult mice [46], but grain counts over bone cells were so low that the possibility of labelling error was very high. These experiments were repeated [71] using the electron microscope to examine mononuclear cells as a marker for a rejection mechanism. The presence of lymphocytes around bone was interpreted to indicate a donor origin of the bone cells, but the data do not provide insight on whether periodontal osteoblasts arise from a stem cell common to fibroblasts, cementoblasts and osteoblasts. In experiments using recombination of mouse dental papilla and dental sac in ocular grafts, there was formation of fibrous connective tissue resembling PL and bone, which appeared similar to alveolar bone [72].

The number of cells labelled with ${ }^{3} \mathrm{H}-\mathrm{Tdr}$ (designated as osteoprogenitors) [62] in the orthodontically stimulated PL peaks several hours after the number of labelled fibroblasts when multiple injections of ${ }^{3} \mathrm{H}-\mathrm{Tdr}$ are given. In a pulselabel experiment, osteoblasts were never observed to be labelled $1 \mathrm{~h}$ after injection, and after multiple labelling, labelled osteoblasts were never observed up to $34 \mathrm{~h}$ after stimulation. From these data, pre-osteoblasts were considered to be either 
$\mathrm{G}_{1}$ or $\mathrm{G}_{2}$ blocked, in which case they either could become two functional osteoblasts or go through only one mitosis prior to becoming functional osteoblasts. There is an apparently separate proliferative response in mouse PL adjacent to bone after wounding [40], indicating that a separate population of bone progenitors may exist. After orthodontic stimulation and multiple labelling by ${ }^{3} \mathrm{H}-\mathrm{Tdr}$ to detect proliferating cells, PL fibroblasts evolved into local osteoblasts on the alveolar bone surface [62]. This report also indicated similarities of the rates of increase of labelling index between PL fibroblasts and osteoblasts, which was cited as indirect evidence that PL fibroblasts are the source of the osteoblasts.

As yet, there is no definitive evidence for the origin of osteoblasts in the PL. It is known that after extirpating PL from teeth, subsequent wound healing will result in the formation of a bony union between cementum and alveolar bone. If the ligament is allowed to remain on the tooth root after removal of the overlying bone, it will become necrotic but will prevent osteogenesis and ankyloses [73]. These findings indicate that some factor(s) in the PL inhibits osteogenesis and preserves the fibrous domain of the ligament, which was shown subsequently to involve prostaglandin E2 [74]. This is a curious finding because the PL may then, under different circumstances, serve both to provide osteoprogenitor cells and to inhibit their differentiation and expression as osteogenic cells. This phenomenon suggests that the cells of the PL regulate and coordinate all osteogenic, cementogenic and fibrogenic activities occurring within its domain. The nature of these regulatory mechanisms is unknown.

\section{Cementoblasts}

The origin of cementoblasts has been examined in transplantation and kinetic experiments [46]: cementoblasts were derived from the cells of the dental follicle, and ${ }^{3} \mathrm{H}$-Tdr labelling of donor cementoblasts was heavy. A wound healing study in cats [75] suggested that cementoblasts differentiate from the fibroblasts adjacent to the denuded cementum surface. However, it was difficult to assign cell lineage with certainty because of a lack of distinct markers for cementoblasts and their precursor cells. After injection of ${ }^{3} \mathrm{H}-\mathrm{Tdr}$ into adult rats and sacrifice $1 \mathrm{~h}$ later, cementoblast labelling was $\sim 25 \%$ of the value of osteoblast labelling indices [53]. The highest labelling indices were observed in the bifurcation of the root where there is virtually no cementum deposition [76], and there were somewhat lower labelling indices measured at the middle and apical levels of the root. As cementogenesis is greatest around the apical part of the root [76], it is difficult to see how one can relate this pattern of cell labelling with cementogenesis.

Mice exhibit much lower rates of cell proliferation in periodontal tissues than rats, and with aging, both cementoblast and osteoblast proliferation decreases rapidly, presumably a response to reduced growth and metabolic function [59]. What is interesting is that the amount of cementum deposited on the apical portion of the root increases with age while the labelling index of cementoblasts decreases in this area. These data further support the belief that the proliferation of cells and the synthesis of mineralized extracellular matrix are unrelated events in the PL.

\section{Conclusions}

The PL is a very narrow, soft fibrous ligament in which cells expressing three distinct phenotypes (bone, cementum and fibrous connective tissue) enable homeostasis and regenerative processes in the periodontium. The progenitor cells of the PL stimulated by wounding $[34,40]$ and orthodontic tooth movement [41] were characterized in terms of their kinetics, spatial distribution and cytology. Wounding induces repopulation of the damaged PL by PL cells; in contrast, orthodontic forces cause a complex response which involves remodelling of alveolar bone and PL to accommodate the new position of the tooth [77]. The pioneering studies described above were not able to resolve whether there were three different progenitor cells for each of the cementoblast, fibroblast and osteoblast populations or whether a single progenitor cell gives rise to all three synthetic cells. In spite of the experimental limitations, data obtained from cell kinetic, wounding and transplantation experiments conducted more than 35 years ago have been instrumental in paving the way for a measured and logical approach to harnessing the potential power of stem cell biology to produce improved outcomes for periodontal therapy. While this promise has not yet been realized in the clinic, current trends reviewed in other papers in this issue point to a bright future.

\section{Compliance with Ethics Guidelines}

Conflict of Interest Dr. McCulloch has no conflict of interest.

Human and Animal Rights and Informed Consent This article does not contain any studies with human or animal subjects performed by any of the authors.

\section{References}

1. Page RC, Schroeder HE. Current status of the host response in chronic marginal periodontitis. J Periodontol. 1981;52:477-91.

2. Hynes K, Menicanin D, Gronthos S, Bartold PM. Clinical utility of stem cells for periodontal regeneration. Periodontol 2000. 2012;59: 203-27.

3. Melcher AH. Periodontal ligament. In: Bhaskar SN, editor. IN Orban's oral histology and embryology. Toronto: Mosby; 1980. p. 204-39. 
4. Melcher AH. The connective tissues of the periodontium. In: Melcher AH, Bowen WH, editors. IN Biology of the periodontium. New York: Academic; 1969. p. 167-343.

5. Sodek J. A comparison of the rates of synthesis and turnover of collagen and non-collagen proteins in adult rat periodontal tissues and skin using a microassay. Arch Oral Biol. 1977;22:655-65.

6. Al-Barwari SE, Potten CS. Regeneration and dose-response characteristics of irradiated mouse dorsal epidermal cells. Int J Radiat Biol Relat Stud Phys Chem Med. 1976;30:201-16.

7. Prichard J. Regeneration of bone following periodontal therapy; report of cases. Oral Surg Oral Med Oral Pathol. 1957;10:247-52.

8. Melcher AH. On the repair potential of periodontal tissues. J Periodontol. 1976;47:256-60.

9. Leblond CP. The life history of cells in renewing systems. Am J Anat. 1981;160:114-58.

10. Scragg MA, Johnson NW. Epithelial cell kinetics - a review of methods of study and their application to oral mucosa in health and disease. Part A Methods Stud Cell Prolif Some Sources Var J Oral Pathol. 1980;9:309-41.

11. Howard A, Pelc SR. Synthesis of deoxyribonucleic acid in normal and irradiated cells and its relation to chromosome breakage. Heredity. 1953;6:261-73.

12. Leblond CP, Messier B, Kopriwa B. Thymidine-H3 as a tool for the investigation of the renewal of cell populations. Lab Investig $\mathrm{J}$ Techn Methods Pathol. 1959;8:296-306. discussion 306-298.

13. Leblond CP. Classification of cell populations on the basis of their proliferative behavior. Natl Cancer Inst Monogr. 1964;14:119-50.

14. Cameron IL. Cell renewal in the organs and tissues of the nongrowing adult mouse. Texas Rep Biol Med. 1970;28:203-48.

15. McCulloch CA, Melcher AH. Continuous labelling of the periodontal ligament of mice. J Periodontal Res. 1983;18:231-41.

16. Messier B, Leblond CP. Cell proliferation and migration as revealed by radioautography after injection of thymidine-H3 into male rats and mice. Am J Anat. 1960;106:247-85.

17. Potten CS. Cell replacement in epidermis (keratopoiesis) via discrete units of proliferation. Int Rev Cytol. 1981;69:271-318.

18. Lajtha LG. Stem cell concepts. Nouv Rev Fr Hematol. 1979;21:5965 .

19. Becker AJ, McCulloch EA, Siminovitch L, Till JE. The effect of differing demands for blood cell production on DNA synthesis by hemopoietic colony-forming cells of mice. Blood. 1965;26:296308.

20. Potten CS. The epidermal proliferative unit: the possible role of the central basal cell. Cell Tissue Kinet. 1974;7:77-88.

21. Grisham JW. A morphologic study of deoxyribonucleic acid synthesis and cell proliferation in regenerating rat liver; autoradiography with thymidine-H3. Cancer Res. 1962;22:842-9.

22. Everett NB, Perkins WD. Haemopoietic stem cell migration. In: Cairnie AB, Lala PK, Osmond DG, editors. IN Stem cells of renewing cell populations. New York: Academic; 1976. p. 221.

23. Leblond $\mathrm{CP}$, Cheng $\mathrm{H}$. Identification of stem cells in the small intestine of the mouse. In: Cairnie AB, Lala PK, Osmond DG, editors. IN Stem cells of renewing cell populations. New York: Academic; 1976. p. 7-32.

24. Lavker RM, Sun TT. Heterogeneity in epidermal basal keratinocytes: morphological and functional correlations. Science (New York, NY). 1982;215:1239-41.

25. Monette FC. Antibodies against pluripotent stem cells: their use in studying stem cell function. Blood Cells. 1979;5:175-91.

26. Till JE. Regulation of haemopoietic stem cells. In: Cairnie AB, Lala PK, Osmond DG, editors. IN Stem cells of renewing cell populations. New York: Academic; 1976. p. 143-56.

27. Till JE, Mc CE. A direct measurement of the radiation sensitivity of normal mouse bone marrow cells. Radiat Res. 1961;14:213-22.
28. Wu AM, Till JE, Siminovitch L, McCulloch EA. A cytological study of the capacity for differentiation of normal hemopoietic colony-forming cells. J Cell Physiol. 1967;69:177-84.

29. Potten CS. Identification of clonogenic cells in the epidermis and the structural arrangement of the epidermal proliferative unit. In: Cairnie AB, Lala PK, Osmond DG, editors. IN Stem cells of renewing cell populations. New York: Academic press; 1976. p. 91-102.

30. Cairns J. Mutation selection and the natural history of cancer. Nature. 1975;255:197-200.

31. Potten CS, Hume WJ, Reid P, Cairns J. The segregation of DNA in epithelial stem cells. Cell. 1978;15:899-906.

32. Mackenzie IC. Spatial distribution of mitosis in mouse epidermis. Anat Rec. 1975;181:705-10.

33. McCulloch CA, Melcher AH. Cell density and cell generation in the periodontal ligament of mice. Am J Anat. 1983;167:43-58.

34. Gould TR, Melcher AH, Brunette DM. Migration and division of progenitor cell populations in periodontal ligament after wounding. J Periodontal Res. 1980;15:20-42.

35. McCulloch CA, Nemeth E, Lowenberg B, Melcher AH. Paravascular cells in endosteal spaces of alveolar bone contribute to periodontal ligament cell populations. Anat Rec. 1987;219:23342.

36. Ross R, Everett NB, Tyler R. Wound healing and collagen formation. VI The origin of the wound fibroblast studied in parabiosis. J Cell Biol. 1970;44:645-54.

37. Kimmel D, Jee WSS. A rapid plastic embedding technique for preparation of three micron thick sections. In: Jaworski ZFG, editor. IN Bone morphometry. Ottawa: University of Ottawa Press; 1976.

38. Roberts WE, Aubert MM, Sparaga JM, Smith RK. Circadian periodicity of the cell kinetics of rat molar periodontal ligament. Am J Orthod. 1979;76:316-23.

39. Chambers DW, Roberts WE, Perko J, Grigas EJ. Variance analysis of experimental design in a study of osteoclast histogenesis. J Dent Res. 1980;59:534.

40. Gould TR, Melcher AH, Brunette DM. Location of progenitor cells in periodontal ligament of mouse molar stimulated by wounding. Anat Rec. 1977;188:133-41.

41. Roberts WE, Chase DC. Kinetics of cell proliferation and migration associated with orthodontically-induced osteogenesis. J Dent Res. 1981;60:174-81.

42. Line SE, Polson AM, Zander HA. Relationship between periodontal injury, selective cell repopulation and ankylosis. J Periodontol. 1974;45:725-30.

43. Virchow R. Die cellular pathologie (Berlin). In: Quoted in Allgower M, Thomas CC, editor The cellular basis of wound repair (1956). Springfield; 1871 .

44. Maximow A. Development of non-granular leukocytes into polyblasts and fibroblasts in vitro. Proc Soc Exp Biol Med. 1926;24:570-2.

45. Golde DW, Hocking WG, Quan SG, Sparkes RS, Gale RP. Origin of human bone marrow fibroblasts. Br J Haematol. 1980;44:183-7.

46. Ten Cate AR, Mills C, Solomon G. The development of the periodontium. A transplantation and autoradiographic study. Anat Rec. 1971;170:365-79.

47. ten Cate AR. Cell division and periodontal ligament formation in the mouse. Arch Oral Biol. 1972;17:1781-4.

48. Freeman E, ten Cate AR. Development of the periodontium: an electron microscopic study. J Periodontol. 1971;42:387-95.

49. Yee JA. Response of periodontal ligament cells to orthodontic force: ultrastructural identification of proliferating fibroblasts. Anat Rec. 1979;194:603-14.

50. Boyko GA, Melcher AH, Brunette DM. Formation of new periodontal ligament by periodontal ligament cells implanted in vivo after culture in vitro. A preliminary study of transplanted roots in the dog. J Periodontal Res. 1981;16:73-88. 
51. Marmary Y, Brunette DM, Heersche JN. Differences in vitro between cells derived from periodontal ligament and skin of Macaca irus. Arch Oral Biol. 1976;21:709-16.

52. Macapanpan LC, Meyers J, Weinmann JP. Mitotic activity of fibroblasts after damage to the periodontal membrane of rat molars. J Periodontol. 1954;25:105-12.

53. Weiss R, Stahl SS, Tonna EA. Functional demands on the cell proliferative activity of the rat periodontium studies autoradiographically. J Dent Res. 1968;47:1153-7.

54. Rippin JW. Collagen turnover in the periodontal ligament under normal and altered functional forces. I. Young rat molars. J Periodontal Res. 1976;11:101-7.

55. Sodek J, Brunette DM, Feng J, Heersche JN, Limeback HF, Melcher AH, et al. Collagen synthesis is a major component of protein synthesis in the periodontal ligament in various species. Arch Oral Biol. 1977;22:647-53.

56. Jensen JL, Toto PD. Radioactive labeling index of the periodontal ligament in aging rats. J Dent Res. 1968;47:149-53.

57. Hayflick L, Moorhead PS. The serial cultivation of human diploid cell strains. Exp Cell Res. 1961;25:585-621.

58. Kontermann K, Bayreuther K. The cellular aging of rat fibroblasts in vitro is a differentiation process. Gerontology. 1979;25:261-74.

59. Tonna EA, Weiss R, Stahl SS. The cell proliferative activity of parodontal tissues in aging mice. Arch Oral Biol. 1972;17:969-82.

60. Cleaver JE. Thymidine metabolism and cell kinetics. Amsterdam: North Holland Pub; 1967.

61. Roberts WE, Jee WS. Cell kinetics of orthodontically-stimulated and non-stimulated periodontal ligament in the rat. Arch Oral Biol. 1974;19:17-21.

62. Yee JA, Kimmel DB, Jee WS. Periodontal ligament cell kinetics following orthodontic tooth movement. Cell Tissue Kinet. 1976;9: 293-302.

63. Smith RK, Roberts WE. Cell kinetics of the initial response to orthodontically induced osteogenesis in rat molar periodontal ligament. Calcif Tissue Int. 1980;30:51-6.

64. Roberts WE, Chase DC, Jee SS. Counts of labelled mitoses in the orthodontically-stimulated periodontal ligament in the rat. Arch Oral Biol. 1974;19:665-70.
65. Roberts WE, Smith RK, Klingler E. Origin of osteoblasts in orthodontically stimulated periodontal ligament. J Dent Res. 1982;61: 183.

66. Owen M. Histogenesis of bone cells. Calcif Tissue Res. 1978;25: 205-7.

67. Sahebekhtiari HA, Tavassoli M. Studies on bone marrow histogenesis: morphometric and autoradiographic studies of regeneration marrow stroma in extramedullary autoimplants and after evacuation of marrow cavity. Cell Tissue Res. 1978;192:437-50.

68. Patt HM, Maloney MA. Regulation of stem cells after local bone marrow injury: the role of an osseous environment. In: Cairnie AB, Lala PK, Osmond DG, editors. IN Stem cells of renewing cell populations. New York: Academic; 1976. p. 239-53.

69. Friedenstein AJ. Precursor cells of mechanocytes. Int Rev Cytol. 1976;47:327-59.

70. Owen M. The origin of bone cells in the postnatal organism. Arthritis Rheum. 1980;23:1073-80.

71. Ten Cate AR, Mills C. The development of the periodontium: the origin of alveolar bone. Anat Rec. 1972;173:69-77.

72. Yoshikawa DK, Kollar EJ. Recombination experiments on the odontogenic roles of mouse dental papilla and dental sac tissues in ocular grafts. Arch Oral Biol. 1981;26:303-7.

73. Melcher AH. Repair of wounds in the periodontium of the rat. Influence of periodontal ligament on osteogenesis. Arch Oral Biol. 1970;15:1183-204.

74. Ogiso B, Hughes FJ, Melcher AH, McCulloch CA. Fibroblasts inhibit mineralised bone nodule formation by rat bone marrow stromal cells in vitro. J Cell Physiol. 1991;146:442-50.

75. Nalbandian J, Frank RM. Electron microscopic study of the regeneration of cementum and periodontal connective tissue attachment in the cat. J Periodontal Res. 1980;15:71-89.

76. Armitage G. Cementum. In: Bhaskar SN, editor. IN Orban's oral histology and embryology. Saint Louis: Mosby; 1976. p. 182-205.

77. Roberts WE. Cell kinetic nature and diurnal periodicity of the rat periodontal ligament. Arch Oral Biol. 1975;20:465-71. 